\title{
Dentistry and aviation engineering - behind the scenes at operations in a UK-based airline
}

\author{
Mohammed Dungarwalla ${ }^{1,2 *}$ and Edmund Bailey ${ }^{1,2}$
}

\section{Key points}

There has been substantive focus on human factors and their interaction with decisionmaking in healthcare.
The authors present themes garnered from an interview with a base maintenance manager from one of the UK's largest airlines.
There are clear overlaps between engineering and dentistry, specifically pertaining to equipment regulation, checklists and working directives.

\begin{abstract}
The healthcare industry is commonly compared to the aviation industry with emphasis on human factors and the decision-making processes undertaken by pilots and clinicians alike. The authors have been given exclusive access to meet the head of the maintenance team behind one of the UK's most popular airlines. An open-ended interview took place which was audio-transcribed for thematic analysis. Data were initially coded to identify basic patterns in the transcript. Once this was completed, themes were identified and agreed between the authors which could be compared to healthcare and dentistry. These themes were: regulation, occupational health, maintenance of equipment, use of checklists, reporting, just culture, burnout and disturbances.
\end{abstract}

The aviation engineering industry requires the combination of a skilled workforce working under time pressure often in a financially restricted environment in a similar way to healthcare, especially dentistry. The two industries share common risks, although introduction of risk management tools such as checklists have been prevalent in aviation since the 1930s. Recognition of said risks and themes can lead to shared learning opportunities to benefit both sectors.

\section{Background}

The awareness of human factors playing a key role in how we conduct our professional and non-professional lives has come to the forefront of healthcare in recent years. It is not uncommon to attend a continuing professional development event with a lecture or workshop on the subject of human factors. Increasingly, these talks are given by our peers in professions not related to healthcare - the aviation sector being a common discipline. The authors were given an exclusive insight into engineering practice at a UK-based airline.

The authors have consent from all relevant parties to publish the findings in this manuscript.

IInstitute of Dentistry, Barts and The London School of Medicine and Dentistry, Queen Mary University of London London, UK; ${ }^{2}$ Department of Oral \& Maxillofacial Surgery,

The Royal London Hospital, Whitechapel, London, UK.

*Correspondence to: Mohammed Dungarwalla

Email address: m.dungarwalla@qmul.ac.uk

Refereed Paper.

Accepted 17 August 2020

https://doi.org/10.1038/s41415-021-3127-4
Although there are numerous studies comparing aviation to medicine and surgery, $1,2,3,4,5,6,7,8,9,10$ to our knowledge, this is the first piece which compares aviation engineering to healthcare and dentistry. Table 1 outlines the themes discussed.

\section{Into the hangar and equipment regulations}

Having been given exclusive access to the aeroplane hangar situated airside, the experience of safety and security began the moment the authors entered the premises. All staff and visitors are identified by name badges, and a named member of staff is responsible for the visitor(s). Security, as stringent as boarding a flight, required removal of metallic objects and electronic devices as well as bag searches, a commitment by the staff who work here daily.

The hangar base manager's accountabilities include delivery of the compliance of the facilities and the hangar. The use of tools, the staff carrying out work on the aircraft and the staff that are certifying airworthiness of an aircraft fall into the remit of the base maintenance manager. The above duties are stipulated in Regulatory Article (RA) 4810 Technical Information (MRP 145.A.45).

RAs provide a framework of rules and policies which dictate the direction of processes which contribute to air safety. The article recognises that failure to adhere to published technical information can pose a risk to life. Furthermore, it requires organisations to have systems in place which allow 'unsatisfactory features' to be reported. ${ }^{11}$

The base maintenance manager must ensure that activity within the hangar satisfies Provision and Use of Work Equipment Regulations (PUWER) 1998 and Lifting Operations and Lifting Equipment Regulations (LOLER) $1998 .^{12,13}$

PUWER places onus on organisations or individuals who use equipment in the workplace to maintain safety while using such equipment. Equipment must be safe for its intended use, maintained in a safe condition and used by those who have received appropriate training to do so. ${ }^{12}$ 
Table 1 Table outlining and comparing themes relevant to dentistry and aviation engineering

\begin{tabular}{|c|c|c|}
\hline Theme & Dentistry & Aviation engineering \\
\hline $\begin{array}{l}\text { Training and } \\
\text { regulation }\end{array}$ & $\begin{array}{l}\text { Formal training pathway with a university degree and subsequent registration with a } \\
\text { professional body }\end{array}$ & $\begin{array}{l}\text { Formal training via a national diploma, university degree } \\
\text { or apprenticeship. Licence recognised as per the European } \\
\text { Aviation Safety Agency }\end{array}$ \\
\hline $\begin{array}{l}\text { Equipment } \\
\text { regulations }\end{array}$ & $\begin{array}{l}\text { Health and Safety at Work Act, Management of Health and Safety at Work Act, } \\
\text { Pressure Safety Systems Regulations, Electricity at Work Regulations, Medical Devices } \\
\text { Regulations, Personal Protective Equipment at Work Regulations, Ionising Radiation } \\
\text { Regulations, lonising Radiation (Medical Exposure) Regulations }\end{array}$ & $\begin{array}{l}\text { Health and Safety at Work Act, Management of Health and } \\
\text { Safety at Work Act, Pressure Safety Systems Regulations, } \\
\text { Electricity at Work Regulations, Personal Protective } \\
\text { Equipment at Work Regulations, Provision of Use of Work } \\
\text { Regulations, Lifting Operations and Lifting Equipment } \\
\text { Regulations }\end{array}$ \\
\hline $\begin{array}{l}\text { Risks in the } \\
\text { workplace }\end{array}$ & $\begin{array}{l}\text { Repetitive strain injury, transmission of infectious diseases via aerosols and direct } \\
\text { inoculation (sharps injury), burnout }\end{array}$ & $\begin{array}{l}\text { Falling from heights, hand-arm vibration syndrome, } \\
\text { repetitive strain injury, inhalation of noxious substances, } \\
\text { cuts and abrasions from equipment, burnout }\end{array}$ \\
\hline $\begin{array}{l}\text { Working } \\
\text { patterns }\end{array}$ & $\begin{array}{l}\text { In general practice, working hours can be self-determined. WTDs apply for all of those } \\
\text { working in training posts in line with the new Junior Doctors' Contract }\end{array}$ & $\begin{array}{l}\text { WTDs apply and engineers do not work for more than } 12 \\
\text { days out of } 14 \text { or for more than two weekends in a row }\end{array}$ \\
\hline $\begin{array}{l}\text { Reporting } \\
\text { safety incidents }\end{array}$ & $\begin{array}{l}\text { Encouraged and mandated but currently there are multiple reporting systems, lack of a } \\
\text { national feedback system and potentially reluctance by individuals to report due to fear } \\
\text { of reprisal. A fair blame culture is actively encouraged }\end{array}$ & $\begin{array}{l}\text { Encouraged and mandated with a learning system in } \\
\text { place, with an aim to prevent the same incident from } \\
\text { occurring again. Engineering safety reports are used } \\
\text { to report incidents. A fair blame culture is actively } \\
\text { encouraged }\end{array}$ \\
\hline
\end{tabular}

In general practice, the practice principal may be involved in making overarching decisions relating to treatment, patient safety and general operation of the practice. Seniority in the The practice manager - often a non-registered team member - will be key in ensuring workplace compliance is delivered properly. In hospital, care is consultant-led and final decisions will rest with the consultant. Consultants train junior clinicians. Overarching decisions on overall delivery of care are made by senior managers. Raising concerns is encouraged although it is rarely direct to managerial level

\begin{tabular}{l|l}
\hline Use of & Not commonplace in general practice. Commonly used in hospital settings (based on \\
checklists & WHO surgical safety checklists) for invasive surgery (including dento-alveolar surgery).
\end{tabular} WHO surgical safety checklists) for invasive surgery (including dento-alveolar surgery).
Risk of retrospective completion

Senior engineers will be assigned to safety-critical tasks and are also responsible for training junior engineers. Challenging seniority is encouraged when justified

Routinely used in aviation and aviation engineering. In the cockpit, checklist completion occurs in real time, removing the risk of retrospective completion

Use is commonplace in general practice and hospital. Often used to communicate with Using mobile colleagues and for video consultations with patients. Useful in instances where hospital phones in the bleeps or pagers are inaccessible. Workplaces will have information governance phones in the policies relating to use of mobile phones in patient environments although monitoring
workplace this activity remains varied. A recognised distraction and risk of perceived lack of professionalism

Commonly used in the hangar. Engineers encouraged to lock phones away as they are a recognised distraction
LOLER regards lifting and lifting equipment. Aircraft maintenance and repairs are often carried out at height, and so this regulation forms the backbone of aviation engineering safety. ${ }^{13}$

In healthcare, the Medicines and Healthcare products Regulatory Agency (MHRA) have provided specific guidance on the acquisition, selection, training, maintenance, disinfection and decommissioning of devices, which includes equipment used in dentistry which is further underpinned by the EU Regulation on Medical Devices 2017/745 (Figures 1 and 2). ${ }^{14}$

\section{Hand-arm vibration syndrome and musculoskeletal disorders}

Hand-arm vibration syndrome (HAVS) is a well-described consequence of repetitive and overuse of equipment which delivers vibrations to the hands. HAVS can affect fine motor skills and sensation to the hands and fingers. ${ }^{15}$ The condition is also associated with a condition known as 'white finger' which describes the painful, often irreversible blanching of fingers which is clinically a secondary type of Raynaud's phenomenon, potentially leading to loss of function in the affected digits. ${ }^{16}$ The Control of Vibration at Work Regulations are concerned with the prevention of HAVS and the safe use of equipment which has been identified in the aetiology of HAVS. Tools in the aircraft hangar are marked red, yellow and green. Each of these tools has a specified 'trigger time' which prevents equipment from being used over a designated period. Equipment usage time is measured by the number of minutes that air flows through the piece of hand equipment. The effect is cumulative and thus engineers can use several pieces of equipment in a day. We are told the threshold is rarely exceeded and, in the case where it is exceeded, a worker is substituted by another engineer.

The use of air-driven equipment and hand instruments is commonplace in dentistry; however, there is no specific regulation pertaining to their overuse, even though their deleterious effects are well documented. ${ }^{17,18,19,20}$ In a study of 220 dentists, $92 \%$ of dentists reported musculoskeletal disorders with their neck and lower backs, and $18.3 \%$ reported pain in their wrists. ${ }^{17}$ Similarly, a separate study found up to $69.5 \%$ of dental hygienists reported pain in their hands and wrists. ${ }^{18}$ Moreover, in a group of dentists surveyed regarding the cause for their taking early retirement due to ill health, 55\% cited musculoskeletal disorder as the primary cause for early retirement. ${ }^{19}$ Coupled with the fact that in 2019, one dental income protection firm paid out approximately $£ 1$ million in claims related to musculoskeletal disorders, ${ }^{20}$ this is clearly an issue which significantly affects the entire dental team. 


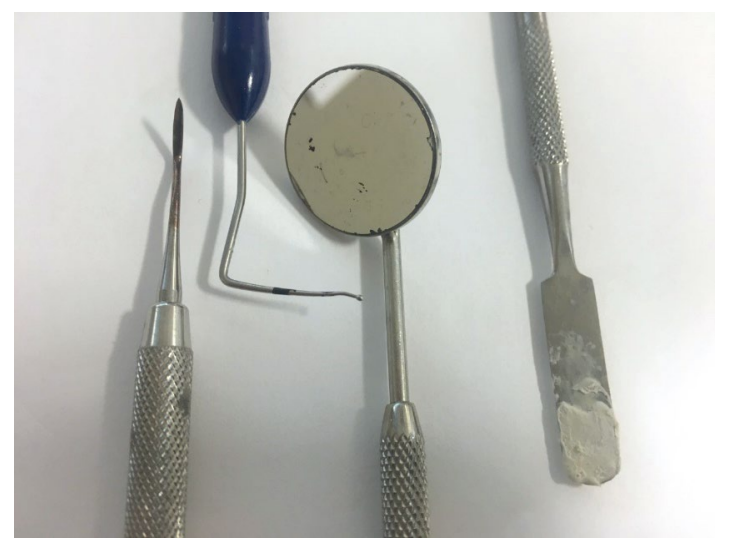

Fig. 1 Dental instruments which are contaminated and/or damaged. Who takes the responsibility in ensuring these instruments are routinely inspected, safely taken out of circulation, disposed of correctly and replaced promptly? Image courtesy of Sally McFadyen, Institute of Dentistry, Queen Mary University of London

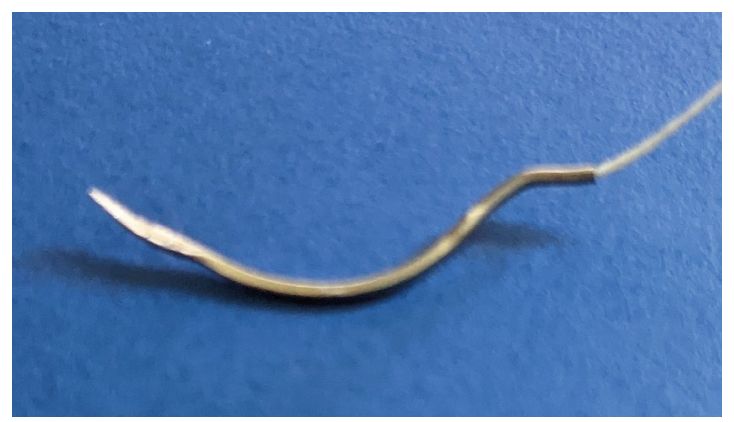

Fig. 2 Repeated use of this suture needle has resulted in its deformation and blunting of the needle tip. Regular peri-operative inspection of the needle must take place to prevent damage to the tissues

\section{Checklists}

The authors acknowledge the relatively recent uptake of checklists in the medical and dental profession, conceived from the World Health Organisation (WHO) Surgical Safety Checklist in $2008 .{ }^{21}$ In the authors' experience, checklists are more often used in a secondary care setting for dentoalveolar surgery, with their uptake in primary care variable. As a stark contrast, checklists within the aviation industry have been present far longer and are ingrained within the flying and engineering component. The introduction of checklists in aviation has its origins from an aeroplane crash in 1935 involving a Boeing B-17 aeroplane where the gust locks (a lock which keeps flying surfaces rigid while the aircraft is on the ground) were not disengaged before take-off. ${ }^{22}$ There was no evidence of equipment malfunction and so investigators were led to believe that pilot error was the cause of the crash, simply due to the immense number of functions on the aircraft which were beyond the capacity of a pilot to operate simultaneously. As such, the pilots were too overwhelmed to disengage the gust locks, leading to the fateful incident. ${ }^{22}$ As a result of this accident, Boeing introduced the checklist as a mandatory tool to be used in military and eventually commercial aviation. ${ }^{23}$

Checklists are recorded in real time onto the cockpit voice recorder. The danger within the medical and dental profession is the retrospective completion of checklists following completion of a procedure, which has the potential to demote it as another meaningless piece of paperwork.

When a plane is experiencing an emergency during flight, the more senior pilot will take control of the aircraft (even if the first officer is in control at that moment in time). Pilots will then use a Quick Reference Handbook and complete a checklist accordingly.

All faults are written in a technical log after the plane has landed and this is a mandatory requirement as it forms the communication bridge between the pilots and engineering team.
A comparison to healthcare to note here is that recordings from the cockpit voice recorder are not subject to routine auditing or scrutiny unless an incident occurs.

\section{Reporting technical issues}

Measurements and parameters from the aircraft are constantly being recorded on the flight data recorder, and in newer aircrafts, these measurements are sent remotely to centres on the ground, which can detect issues as they arise inflight without the pilots even knowing that an issue may have arisen.

In instances where pilots have deviated from the checklist, this will be recorded by the flight data recorder (for example, not having landing gear deployed and locked ready for landing above a minimum threshold height) and sent to the relevant monitoring centre. Regardless of this, pilots are still expected to report this deviation/near miss once it has happened.

Similarly, aircraft engineers are required to file engineering safety reports if there has been an incident or near miss.

Reporting systems within healthcare do exist, including Datix, the Yellow Card Scheme (operated by the MHRA) and the NHS Improvement Patient Safety Reporting Tool. These systems rely on honest, accurate and contemporary reporting of incidents from healthcare professionals.

In UK healthcare, as part of the Five Year Forward View, the patient safety incident management system (PSIMS) is being developed in order to include reporting of incidents from settings other than acute care and from patients themselves, and to reduce the overlap of reporting which exists between the Yellow Card Scheme (MHRA) and the National Reporting and Learning System. ${ }^{24}$

The goal is the utilisation of a single infrastructure which encourages reporting by professionals and patients, the collection of transparent data, direct feedback to providers and resources to share with other providers to aid learning. ${ }^{24}$

\section{Just culture and burnout}

Following on from reporting near misses and adverse incidents, just culture and appropriate raising of concerns deserves mention, especially as just culture and whistleblowing has seen a phenomenal amount of publicity within healthcare in recent years. ${ }^{25}$ 
One of the factors discussed in both industries is the incentive to drive change. Engaging individuals and teams to adopt a culture which some may perceive as unnecessary has been an obstacle towards achieving just culture. One way this has been overcome is through local training days and engagement projects for team members.

When discussing fatigued workers, it was clear that there is no compromise on workers who declare fatigue. They are immediately relieved from performing a 'safety-critical' task and substituted by an equally skilled replacement.

Similarly, if a pilot declares that they are not fit to fly for reasons beyond their control, then the airline will send a second crew to relieve the pilot(s) of their duties. This could mean that flights are delayed, or even cancelled in some instances. Pilots are guaranteed 12 hours of rest from the point of reaching their residence.

Exploring some of the reasons for mistakes in the engineering hangar, it is clear that a series of mistakes or failures of safeguarding occur before an error becomes apparent. In the aircraft industry, these can lead to catastrophic consequences for staff and passengers.

Reason's Swiss Cheese model has been a commonly cited paradigm to describe such failures. ${ }^{26}$

Many mistakes in the hangar are put down to poor planning. This poor planning, in turn, results in increased time pressure for engineers to complete certain tasks. Due to inadequate planning, engineers may be faced with absent or incorrect equipment to complete a task and may be tempted to improvise with existing equipment.

A prime example of this occurred in 1990 when a flight bound for Malaga experienced sudden decompression and loss of the cockpit window soon after take-off. The result was the captain was partially 'sucked out' of the window, leaving the co-pilot to manoeuvre the aircraft back to land safely. ${ }^{27}$ The investigation found that the engineer responsible for changing the window was under time pressure to complete the task before the plane was scheduled to fly the next morning.

Furthermore, the engineer improvised by using bolts to secure the windscreen which were $0.66 \mathrm{~mm}$ smaller than the prescribed diameter (Fig. 3). ${ }^{27}$ The investigation recognised the need for this task to have been verified by a more senior or equally trained engineer. $^{27}$

Burnout is now a recognised occupational phenomenon by the WHO, characterised by

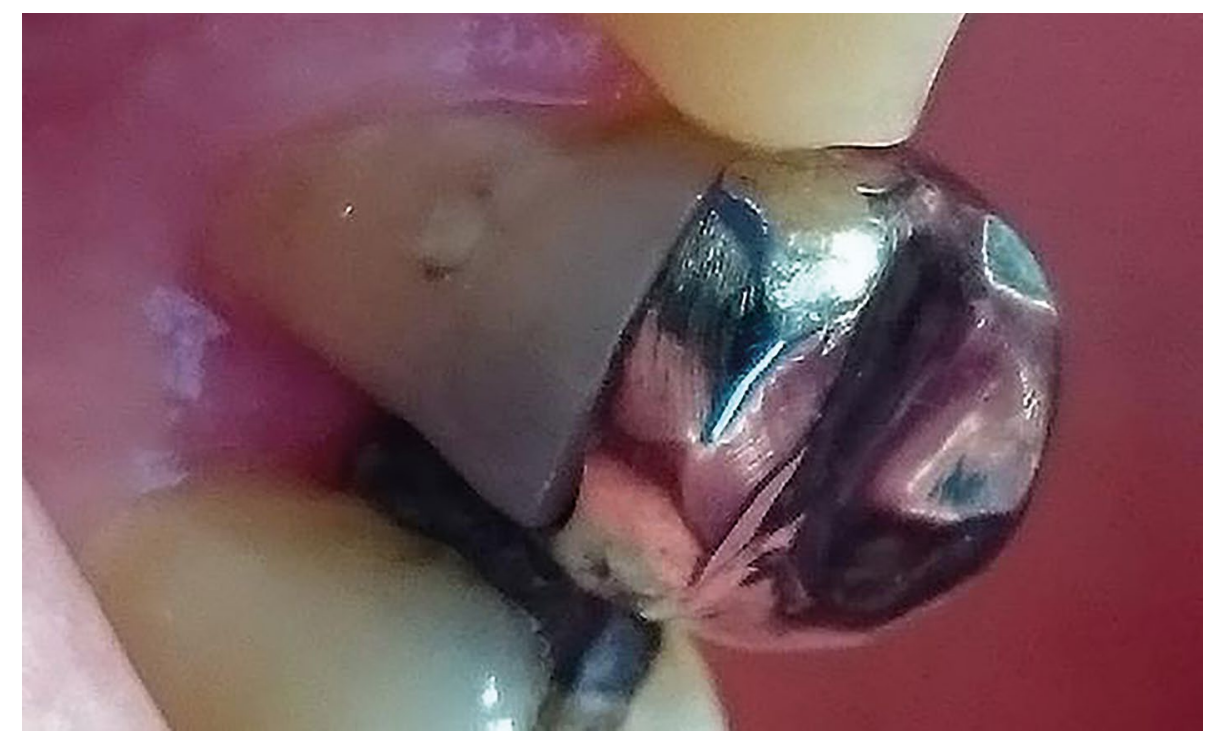

Fig. 3 There is a deficiency of less than one millimetre on try-in of this non-precious metal onlay, which guarantees a plaque trap if accepted as so. The error could have initiated at the time of impression, during casting of the model, during construction of the onlay, or a combination of factors. Auditing work which is remade or sent back to the laboratory is a useful learning tool for clinicians and technicians to understand the root cause

a feeling of exhaustion, reduced professional efficacy and increased mental distance or feelings of negativity towards one's job..$^{28}$ The most concerning study related to our profession found that $54.9 \%$ of dentists from a cohort of 2,053 reported high levels of job stress, with over $17 \%$ of respondents admitting to thinking of suicide. ${ }^{29}$ In particular, the demands of a job, namely role stress, workload, job ambiguity and work pressure, have been cited as causes of burnout. ${ }^{30}$ In contrast, engagement is seen as the polar opposite of burnout and maintaining engagement is likely to improve dentist-patient relationships, clinician wellbeing and job satisfaction. ${ }^{31}$

When comparing burnout in the aviation industry, a 2018 study demonstrated that from a cohort of 1,147 pilots, $40 \%$ reported experiencing 'very high burnout. ${ }^{32}$ Revealingly, the same study demonstrated that two key outcomes, happiness and performance in simulator training, were related to pilot burnout. Namely, the higher the burnout, the greater effect it would have on the pilot's overall wellbeing and, as such, would cause a diminished performance at simulator training. The authors of this study hypothesised that the lack of energy due to burnout resulted in pilots failing to adjust to their optimal preferences when undertaking simulator training. ${ }^{32}$ Whether this can be applied directly to dentistry and dentists operating simulated tasks (or indeed on real patients) remains to be proven.
Additionally, it was demonstrated that insecurity about future employment and work interfering with one's private life was linked to high levels of exhaustion..$^{32,33}$ With the aviation industry being subject to thousands of job losses and even some airlines ceasing trade in recent months, ${ }^{34}$ many dentists have, too, been subject to insecurity regarding their future employment.

\section{Just saying 'no', working time directives and changing the culture}

Engineers are encouraged to report when they do not have the correct equipment and will refuse to complete a task should they feel that safety is being compromised. Furthermore, engineers are encouraged to declare if they do not feel safe carrying out a certain task due to fatigue or lack of skill, even if this results in a delay in the schedule or turnaround of an aircraft.

The lack of challenging seniority within the flight deck deserves mention as it is responsible for several notable incidents in aviation. These have often occurred when less experienced and pliant co-pilots have failed to speak out above their seniors, even when they were aware of a malfunction. In 1999, Korean Air 8509 crashed shortly after departure from Stansted Airport. Accident investigators were flummoxed that the various alarms that could be heard on the cockpit voice recorder were ignored by the 
crew. Investigators concluded that the junior crew members were reluctant to question the actions of the experienced captain (based on cultural tradition), with one description of the junior crew as 'fearing dishonour more than death itself. ${ }^{35}$

Adhering to working time directives (WTDs) is central to the safe practice of engineering within the company. Engineers will never work more than 12 days in 14 and they will never work two weekends in a row. Following the introduction of the controversial reformed junior doctor contract in 2016, among much paroxysmal debate, the document stipulated that no doctor should be rostered for more than 72 hours of work in a consecutive 168hour period and no doctor should be rostered for more than an average of 48 hours per week. ${ }^{36}$ Simultaneously, the duty of 'exception reporting' was introduced which mandated junior doctors to report incidences where they are working unsafe hours or beyond their rostered hours. ${ }^{37}$

For those of our colleagues working in on-call patterns, although the WTDs apply, it is likely that these new regulations will be hard to adhere to and many departments continue to function on the 'goodwill' of their personnel. ${ }^{38}$ This perhaps naturally comes with the role of looking after patients with fluctuating and unpredictable clinical needs.

Less than 20 years ago, it was normal for engineers and doctors alike to be working $72(+)$-hour weeks due to exemption from WTDs, ${ }^{39}$ the perceived need for training and the lack of recognition of how safety-critical tasks were impaired due to fatigue. It was agreed that the newer generation of engineers/ clinicians are more open to reporting these violations and will normalise working in a shift pattern that complies with WTDs. This is further enhanced by the introduction of apprenticeships directly started by airlines which can engrain this culture from the very beginning of training.

Most dentists working in the UK are self-employed. ${ }^{40}$ Arguably, the role offers the possibility of flexible working hours, the freedom to focus on particular skillsets and offer niche services (for example, facial aesthetic work), and the potential to earn financially well. At the same time, however, many self-employed dentists may feel obliged to meet targets of dental activity and, as such, work longer hours to meet these, which raises the possibility of dentists working while exhausted to meet contractual demands.
A recent landmark case concerning a self-employed hairdresser found that the hairdresser should be receiving the benefits of an employee considering that the salon she worked at took a percentage of her earnings and also dictated her working hours. This tribunal hearing may set the precedent for thousands of self-employed dentists, and may change the way in which dentistry is delivered and indeed how it is rewarded in the future. ${ }^{41}$

\section{Do not disturb}

The use of mobile phones in the workplace is a well-recognised phenomenon, and although their advantages are significant, ${ }^{42}$ there is the potential for devices to interrupt and affect the safe execution of a task. In a study of 312 nursing students, $46.2 \%$ used their smartphones during clinical practice, with nearly a quarter $(24.7 \%)$ admitting to being distracted by their phones. ${ }^{43}$ Engineers are given lockers to secure their personal belongings, and close friends and family are given the engineering office number in case of an emergency.

Similarly, in our workplace, there are warnings and notices during induction regarding the use of mobile phones and information governance policy, although in the authors' experience, many clinicians will argue that mobile phones help them to perform their job effectively and safely, and are commonly used in a clinical setting.

Engineers performing safety-critical tasks wear bibs to denote such activity. This has a twofold effect of warning other colleagues not to disturb them during this activity and signposting to other colleagues in that role who is performing a certain aspect of that task.

In our department, there is no clear visible identifier to denote who is carrying out which part of a safety-critical task. Conversely, in theatre settings, blue scrubs are the common attire with only name badges to denote our name and role. In nursing, bibs are given to nurses who are dispensing drugs for patients with a clear notice stating: 'Drug round in progress - do not disturb', ${ }^{44}$ although the uptake for this is not trust-wide, let alone nationwide. Furthermore, some clinicians are now bearing their speciality/role on their scrub hat or apron, which has proven to be useful in major incidents and instances where personal protective equipment remains worn for long periods of time (as seen in the COVID-19 global pandemic).

\section{Root cause analysis and sharing information}

Much of aircraft engineering practice is governed by local regulations, although there are overarching regulations set by the European Union Aviation Safety Agency. The impact of Brexit on compliance with these regulations is unknown, although it is unlikely that there will be any major shifts in practice. The emphasis on root cause analysis is strong and airlines/ engineering firms are mandated to share this information with other providers to prevent the same incident from occurring again.

This is not necessarily the case in healthcare where, although information sharing is promoted, it does not necessarily occur, nor does it necessarily lead to the desired changes. It is possible that past examples of heavyhandedness and unfair penalties by regulatory bodies have scared honest professionals into keeping safety-critical incidents shrouded in secrecy.

This culture, however, is changing for the better. Nationally, there are programmes dedicated to learning about mistakes concerning human errors in healthcare and dentistry, ${ }^{45,46}$ and there is ample literature available relating to developing a safety culture within healthcare. ${ }^{47,48,49,50,51,52}$

\section{Conclusion}

Some of the factors concerning safety in the aviation engineering industry have been highlighted in this piece with comparison to dentistry and the wider healthcare field. There are some factors which share common themes and obstacles. However, it appears that the engineering industry and aviation industry have been able to adopt this approach more swiftly compared to our profession.

Health and safety remain the backbone of both industries, and the sentiment gathered is that there is a passion to maintain and improve safety. Safety defines every action that is undertaken within the aircraft hangar. All actions are there to preserve the health of, and reduce the risk of injury to, one's self and the people around them. Challenges exist and are overcome, some more readily than others, and often learning from our peers in non-healthcare-related industries sets the precedent.

\section{Conflict of interest}

The authors declare no conflicts of interest. 


\section{References}

1. Oeppen R, Davidson M, Scrimgeour D, Rahimi S, Brennan P. Human factors awareness and recognition during multidisciplinary team meetings. J Oral Pathol Med 2019; 48: 656-661.

2. Davidson M, Brennan P. Leading article: What has an Airbus A380 Captain got to do with OMFS? Lessons from aviation to improve patient safety. Br J Oral Maxillofac Surg 2019; 57: 407-411.

3. Seager L, Smith D, Patel A, Brunt H, Brennan P. Applying aviation factors to oral and maxillofacial surgery - the human element. Br I Oral Maxillofac Surg 2013; 51: 8-13.

4. Kao L, Thomas E. Navigating Towards Improved Surgical Safety Using Aviation-Based Strategies. J Surg Res 2008; 145: 327-335

5. Aerden D, Smets D, Poelaert J, Oste J, Brande P. Fighting Human Error: What Surgeons Can Learn from Aviators. Acta Chir Belg 2014; 114: 228-232.

6. Gore D, Powell J, Baer J et al. Crew Resource Management Improved Perception of Patient Safety in the Operating Room. Am J Med Qual 2009; 25: 60-63.

7. de Korne D, van Wijngaarden J, Hiddema U, Bleeker F, Pronovost P, Klazinga N. Diffusing Aviation Innovation in a Hospital in the Netherlands. Jt Comm J Qual Patien Saf 2010; 36: 339-347.

8. Dow I. Simulation in flight safety - what can we learn from the airline industry? Acta Ophthalmol 2017; DOI: 10.1111/j.1755-3768.2017.02621.

9. Broom M, Capek A, Carachi P, Akeroyd M, Hilditch G. Critical phase distractions in anaesthesia and the sterile cockpit concept. Anaesthesia 2011; 66: 175-179.

10. Assael L. "Sully" Sullenberger and the Miracle on the Hudson: A Lesson in Heroism for Oral and Maxillofacial Surgeons. J Oral Maxillofac Surg 2009; 67: 711-712.

11. Ministry of Defence and Military Aviation Authority. Regulatory Article (RA) 2000 series: flying regulations (FLY). 2014. Available online at https:// www.gov.uk/government/publications/regulatoryarticle-ra-2000-series-flying-regulations-fly (accessed February 2020).

12. Health and Safety Executive. Provision and Use of Work Equipment Regulations 1998 (PUWER) - Work equipment and machinery [Internet]. Hse.gov.uk. [cited 3 February 2020]. Available from: https://www.hse.gov. uk/work-equipment-machinery/puwer.htm.

13. Lifting Operations and Lifting Equipment Regulations 1998 (LOLER) - Work equipment and machinery. Available at https://www.hse.gov.uk/work-equipmentmachinery/loler.htm (accessed February 2020).

14. Medicine \& Healthcare products Regulatory Agency. Managing Medical Devices: Guidance for health and social care organisations. 2015. Available at https:// assets.publishing.service.gov.uk/government/uploads/ system/uploads/attachment_data/file/421028/ Managing_medical_devices_-_Apr_2015.pdf (accessed April 2020)

15. Health and Safety Executive. Hand arm vibration - Key messages. Available at https://www.hse.gov.uk/vibration/ hav/keymessages.htm (accessed February 2020).

16. BMJ Best Practice. Raynaud's phenomenon Symptoms, diagnosis and treatment. Available online at https://bestpractice.bmj.com/topics/en-gb/193/ aetiology (accessed May 2020).

17. Kierklo A, Kobus A, Jaworska M, Botuliński B. Workrelated musculoskeletal disorders among dentists - a questionnaire survey. Ann Agric Environ Med 2011; 18: $79-84$
18. Hayes M, Cockrell D, Smith D. A systematic review of musculoskeletal disorders among dental professionals. Int J Dent Hyg 2009; 7: 159-165.

19. Brown J, Burke F, Macdonald E et al. Dental practitioners and ill health retirement: causes, outcomes and re-employment. Br Dent J 2010; 209: E7.

20. Dentists' Provident. 2019 claims statistics. 2020. Available at https://www.dentistsprovident.co.uk/ media/1514/claims-stats-2019.pdf (accessed April 2020)

21. World Health Organisation. WHO Surgical Safety Checklist. 2009. Available online at https://www.who. int/patientsafety/safesurgery/checklist/en/ (accessed April 2020).

22. Ludders J, McMillan M. Errors in veterinary anaesthesia. 1st ed. Ames: Wiley Blackwell, 2017.

23. Boorman D J, Higgins W Y. Checklists to Enhance Safety. 2016. Available at https://www.boeing.com/features/ innovation-quarterly/2019_q3/btj-checklist.page (accessed May 2020).

24. NHS Improvement. The future of the patient safety incident reporting: upgrading the NRLS. 2020. Available online at https://improvement.nhs.uk/news-alerts/ development-patient-safety-incident-managementsystem-dpsims/ (accessed May 2020)

25. Blenkinsopp J, Snowden N, Mannion R et al. Whistleblowing over patient safety and care quality: a review of the literature. J Health Organ Manag 2019; 33: 737-756.

26. Reason J. Human error: models and management. $B M$ 2000; DOI: $10.1136 / \mathrm{bmj} .320 .7237 .768$.

27. Air Accidents Investigation Branch. 1/1992 BAC OneEleven, G-BJRT, 10 June 1990. 2014. Available online at https://www.gov.uk/aaib-reports/1-1992-bacone-eleven-g-bjrt-10-june-1990 (accessed December 2019).

28. World Health Organisation. Burn-out an "occupational phenomenon": International Classification of Diseases. 2019. Available at https:// www.who.int/mental_health/evidence/burn-out/ en/ (accessed April 2020)

29. Anonymous. More than half of dentists say stress is affecting their practice. Br Dent J 2019; 226: 7 .

30. Basson R A. Management and Prevention of Burnout in the Dental Practitioner. 2013. Available at https:// www.longdom.org/open-access/managementand-prevention-of-burnout-in-the-dentalpractitioner-2161-1122.1000168.pdf (accessed May 2021)

31. Lee R, Ashforth B. A meta-analytic examination of the correlates of the three dimensions of job burnout. J Appl Psychol 1996; 81: 123-133.

32. Demerouti E, Veldhuis W, Coombes C, Hunter R. Burnout among pilots: psychosocial factors related to happiness and performance at simulator training. Ergonomics 2018; 62: 233-245.

33. Bakker A B, Demerouti E, Sanz-Vergel A I. Burnout and Work Engagement: The JD-R Approach. Ann Rev Organ Psychol Organ Behav 2014; 1: 389-411.

34. Transport Committee, House of Commons. The impact of the coronavirus pandemic on the aviation sector. 2020. Available at https://publications.parliament. uk/pa/cm5801/cmselect/cmtrans268/26807 htm\#footnote-150 (accessed August 2020).

35. Smithsonian Channel. Cultural Norms Cloud Cockpit Communications. 2013. Available at https://www. youtube.com/watch?v=aG3_nJYtrO8\&t=5s (accessed May 2020).
36. British Medical Association. Terms and Conditions of Service for NHS Doctors and Dentists in Training. 2016. Available online at https://www.bma.org.uk/pay-andcontracts/contracts/junior-doctor-contract/juniordoctor-contract-in-england (accessed May 2020).

37. British Medical Association. Exception reporting for junio doctors. 2020. Available at https://www.bma.org.uk/payand-contracts/working-hours/work-schedule/exceptionreporting-for-junior-doctors (accessed June 2020).

38. Arnold J. Staff goodwill is a critical lifeline for the survival of the NHS. 2019. Available at https://www.hsj.co.uk/ workforce/staff-goodwill-is-a-critical-lifeline-for-thesurvival-of-the-nhs/7025811.article (accessed May 2020)

39. Pickersgill T. The European working time directive for doctors in training. BMJ 2001; DOI: 10.1136/ bmj.323.7324.1266.

40. NHS. Pay for dentists. Available at https://www. healthcareers.nhs.uk/explore-roles/dental-team/rolesdental-team/dentist/pay-dentists (accessed August 2020).

41. UK Government. Ms M Gorman v Terence Paul (Manchester) Ltd. 2020. Available at https://assets.publishing.service.gov.uk/ media/5f2194eed3bf7f1b13f64f69/Ms_M_ Gorman v Terence Paul Manchester Limited_-_2410722_2019.pdf (accessed August 2020).

42. Dungarwalla M, Chapireau D, Bentley R. Use of WhatsApp in an oral and maxillofacial surgery department at a major trauma centre and its role during major incidents: our experience. Br J Oral Maxillofac Surg 2019: 57: 449-453.

43. Cho $\mathrm{S}$, Lee E. Distraction by smartphone use during clinical practice and opinions about smartphone restriction policies: A cross-sectional descriptive study of nursing students. Nurse Educ Today 2016; 40: 128-133.

44. Nursing Times Contributor. The effectiveness of drug round tabards in reducing incidence of medication errors. 2010. Available at https://www.nursingtimes. net/archive/the-effectiveness-of-drug-roundtabards-in-reducing-incidence-of-medicationerrors-30-08-2010/ (accessed May 2020).

45. Black Box Dentistry. Homepage. 2020. Available at http:// www.blackboxdentistry.co.uk/ (accessed January 2020).

46. HSL. Behaviour Change: Achieving Health \& Safety Culture Excellence. Available at https://www.hsl.gov. uk/health-and-safety-training-courses/behaviourchange-achieving-health-safety-culture-excellence (accessed May 2020)

47. Mannion R, Davies H. Understanding organisational culture for healthcare quality improvement. BMJ 2018; DOI: $10.1136 / \mathrm{bmj} . \mathrm{k} 4907$

48. The King's Fund. NHS leadership and culture: our position. 2020. Available at https://www.kingsfund. org.uk/projects/positions/NHS-leadership-culture (accessed May 2020).

49. Jacobs R, Mannion R, Davies H, Harrison S, Konteh F, Walshe $K$. The relationship between organisational culture and performance in acute hospitals. Soc Sci Med 2013: 76: 115-125.

50. Mannion R, Davies H T, Marshall M N. Cultural characteristics of "high" and "low" performing hospitals. $J$ Health Organ Manag 2005; 19: 431-439.

51. Scott T, Mannion R, Davies H T, Marshall M N Implementing culture change in health care: theory and practice. Int J Qual Health Care 2003; 15: 111-118.

52. Verbakel $\mathrm{N} J$, de Bont A A, Verheii T J, Wagner C, Zwart $D \mathrm{~L}$. Improving patient safety culture in general practice: an interview study. Br J Gen Pract 2015; DOI: 10.3399/ bjgp15X687865.

\section{Correction to: Book review: Dental interviews (1st edition) - A comprehensive guide to DCT \& ST interview skills}

The original article can be found online at https://doi.org/10.1038/s41415-021-3027-7.

Author's correction note:

Book review article Br Dent J 2021; 230: 570 .

When this article was initially published the author's name was spelt incorrectly as 'Kirsty Cowen'. The author's name is spelt Kirsty Cowan.

The journal apologises for any inconvenience caused. 